\title{
OS MICRODESERTOS EDÁFICOS NA NEOPAISAGEM DA REGIĀO NOROESTE DO ESTADO DO PARANÁ - BRASIL, COMO REGISTRO DE UM NOVO PERIODO GEOLÓGICO (QUINÁRIO?)
}

\author{
Ana Maria MURATORI \\ Professora Adjunta Departamento de Geografia - UFPR \\ Geógrafo \\ Doutora, em Ciẽncias Florestais - UFPR
}

\begin{abstract}
In the northwest region of Parana State, south of Brazil, occurred great transformations due deforestation and using for cultivation, from 40 decade. Human actuation accelerated processes that modified the existing landscape, determining environment unbalanced condition, how pre-deserted on sandy sedimentary covering, that origin "edaphic micro-deserts ". These conditions induce the idea of anthropic action, that interfere in dynamic environment processes, designing the neo-landscape of the northwest region and connected to a new geologic period, denominated "Quinary" or "Technogene".

KEY WORDS: Edaphic microdeserts; Humam actuation; new landscape; Quinary or Technogene.

\section{RESUMO}

A regiāo noroeste do Estado do Paraná, no sul do Brasil, foi palco de grandes transformaçóes devido à retirada da cobertura florestal $\theta$ intensa ocupaçāo agricola a partir do final da década de 40 . Esta atuação humana acelerou processos que passaram a modificar a paisagem existente, determinando condiçóes de desequilibrio ambiental. Distinguem-se processos relativos à pré-desertificaçāo, na area relativa à cobertura sedimentar arenosa, sob a forma de microdesertos edaficos. Estas condiçōes, por sua vez, induzem a que se aceite a idéia de que a açăo antrópica, que interfere nos processos da dinămica ambiental, estăo desenhando a neopaisagem da região e, relacionandose a um novo periodo geológico, denominado de Quinário ou Tecnógeno.

PALAVRAS-CHAVE: Microdesertos edáficos; açāo antrópica; neopaisagem; Quinário ou Tecnógeno.
\end{abstract}




\section{INTRODUÇĀO}

A regiäo noroeste do Estado do Paraná, na área de dominio do Arenito Caiuá, foi palco de um dos maiores reveses ecológicos brasileiros a partir do final da década de 40, relacionado à eliminação da Floresta Estacional Semidecidual e sua substituição pela agricultura. O beneficio esperado com a retirada da fioresta, através da expansão cafeeira do Estado de Sào Paulo e norte do Paraná, em poucos anos se transformou em prejuizos crescentes devido ao rápido esgotamento dos seus solos, aliado a processos erosivos acelerados, marcadamente, durante as décadas de 60 e 70 .

Atualmente, reconhece-se na região uma certa estabilidade parcial, devido a novas técnicas de manejo e formas de utilizaçäo do solo. No entanto, o cruzamento da ordem natural do meio e sua exploraçāo ainda apresenta obstáculos, uma vez que os solos da regiăo noroeste săo arenosos em sua maior parte, de baixa produtividade e altamente suscetiveis à erosâo, quando comparados a outros solos ocorrentes no Estado do Paraná.

Estes processos, acelerados pela atuaçāo antrópica e que têm alterado significativamente as paisagens estão relacionados, de acordo com TERSTEPANIAN (1988), ao advento de um novo periodo geológico, sucedendo-se ao Quaternário, denominado de Quinário ou Tecnógeno. Está ligado à tecnologia, referindo-se aos eventos desencadeados pela açāo do hornem, os quais, na sua maioria, provocam impactos ao meio ambiente como é o caso da área a que se refere o presente estudo.

Diante do exposto, torna-se importante o conhecimento dos fatores intervenientes no sistema ambiental $\theta$, principalmente os resultados da atuaçăo humana, tendo em vista que, so a partir do entendimento destas questöes, é que se torna possivel propor alternativas que visem um melhor aproveitamento do potencial ecológico que a regiăo noroeste dispōe, considerando-se sua fragitidade natural. Neste sentido, partiu-se de uma caracterizaçăo geográfica da paisagem numa abordagem sistêmica, visando o reconhecimento dos fatores estruturais e conjunturais que contribuem para a delineação da neopaisagem da regiāo noroeste do Paraná, destacando-se algumas áreas especificas as quais se denominou de microdesertos edáficos, em concordảncia com os conceitos dé DREGNE (1977)

O enfoque sistémico prendeu-se à natureza, dinámica evolutiva e interdependéncia dos fenômenos envolvidos. Materializou-se, neste estudo, através das formas de atuação dos fatores abióticos em simbiose com os fatores bióticos que interagem para caracterizar a paisagem.

Após a delimitação espacial do sistema ambiental discriminou-se os processos de natureza endógena e exógena atuantes no seu interior, discutindose seus atributos. Trabalhou-se com os conceitos inerentes à visāo sistêmica, destacando-se matéria, energia, organizaçāo e funcionalidade, em constante evoluçäo através do tempo.

\section{LOCALIZAÇÄO E CARACTERISTICAS DA ÁREA DE ESTUDO}

A regiáo noroeste do Paraná, na área de influência do Arenito Caiuá abrange cerca de $12 \%$ do Estado do Paraná, é limitada pelos rios Paranapanema 
ao norte, rio Paraná a oeste, rio Piquiri ao sul e os terrenos derivados do basalto a leste. Estende-se entre as coordenadas de $23^{\circ}$ e $24^{\circ}$ de Latitude Sul e entre $52^{\circ}$ e $54^{\circ}$ de Longitude Oeste de Gr. (OEA, 1973).

\section{OS FATORES FÍSICOS: GEOLOGIA, CLIMA, RELEVO, VEGETAÇĀO E SOLOS}

Os aspectos relativos à história geológica da região noroeste do Estado do Paraná se prendem à dinámica da Bacia Sedimentar do Paraná com eventos que se sucederam a partir de 450 mithōes de anos, envolvendo avanços marinhos, glaciais, grandes desertos e vulcanismo. Para o afeiçoamento do sistema ambiental presente destaca-se o derrame basálitico (MAACK, 1968), que ocorreu entre 200 milhōes até cerca de 65 milhōes de anos. Foi recoberto parcialmente por arenitos de origem predominanternente é́lica a partir de 95 milhōes de anos que determinaram a Formaçäo Caiuá também denominada de Arenito Caiuá (GIMENEZ et al., 1981; FERNANDES, 1992). Parte deste material retrabalhado, transformou-se numa cobertura cenozóica, a partir do Terciário Médio, denominada de Formação Paranavai. (POPP e BIGARELLA, 1975).

Esta litoestratigrafia fol acompanhada, com maior ou menor intensidade, por eventos tectônicos no decorrer do tempo geológico, sendo sua interferência inferida através de indicios geológico-geomorfológicos como lineamentos e padrōes de drenagem orientados (MURATORI e MURATORI, 1985; MURATORI, 1996).

O clima faz parte do sistema numa atuaçẫo permanente mas com frequêencia diferenciada, destacando-se os episódios a partir do Terciário, quando ocorreram alternâncias de aridez e umidade registradas pela presença da Formaçāo Paranavaí, envolvendo colúvios e cascalheiras (POPP e BIGARELLA. 1975; BIGARELLA e MAZUCHOWSKI, 1985). Na atualidade, as precipitaçōes variam entre 1000 a $1600 \mathrm{~mm}$ anuais $\theta$ as temperaturas médias anuais oscilam em torno de $21^{\circ} \mathrm{C}$ (IAPAR, 1994).

Quanto à mortologia, sua evoluçâo prende-se ao desenvolvimento de superficies de aplainamento, com inicio provável no Oligoceno, destacando-se a superficie denominada de Pd1 (JUSTUS, 1985; BIGARELLA e MAZUCHOWSKI, 1985), a qual é encontrada, generalizadamente, na regiăo de abrangência dos arenitos da Formação Caiuá com altitudes em torno de 400 metros. Embutidos neste nivel, săo encontrados compartimentos, constituindo anfiteatros que comportam vales onde ocorrem processos erosivos acelerados, com presença de vaçorocas e depósitos arenosos.

Em relaçăo à presença de organismos no sistema, destaca-se a fiora, diretamente relacionada às alternâncias climáticas que permitiram, ora a expansāo de formaçōes florestais, ora o predomínio de uma vegetaçăo mais aberta dos cerrados. O último evento, relacionado ao interglacial atualmente em vigência, propiciou o desenvolvimento da Floresta Estacional Semidecidual (FIBGE, 1993) e de acordo com LEITE (1994), de Floresta Estacional Semidecidua Subxérica, O autor, ao descrever a estrutura desta floresta, destacou o fenômeno da semidecidualidade estacional nos estratos arbóreos 
superiores, citando, também, o encrave de savanas como resquícios de uma deficiência litopedológica e clima mais frio e seco do Quaternário.

A presença desta floresta, expandida na área de domínio do Arenito Caluá, impôs uma situaçăo de equilibrio dinàmico ao sistema, segundo MAACK (1947; 1953), verificada através de registros fotográficos da década de 50 , quando parte da floresta ainda estava intacta (MUAATORI, 1984; 1996)

Os fatores geológicos, climáticos, morfológicos e biológicos em interação no tempo, permitiram a elaboração de uma cobertura pedológica, sendo perceptiveis niveis diferenciados, de acordo com o relevo e a atuaçăo climática mais úmida ou mais seca, formando, na atualidade, solos típicos com a presença marcante das areias como seu constituinte principal. Esta cobertura pedológica apresenta como caracteristica uma extrema fragilidade á ação dos agentes intempéricos, sofrendo intensamente a ação de processos erosivos. Mesmo sob a floresta ou logo após o desfiorestamento, conforme fotografias aéreas de 1952 (MURATORI, 1984), foram registradas paleovoçorocas estabilizadas e/ou em processo de reativaçăo, além de depósitos arenosos em torno das mesmas, nas áreas dos anfiteatros de erosão (MURATORI, MURATORI e SALAMUNI, 1985; MURATORI, 1996).

\section{A INTERVENÇĀO ANTRÓPICA NO SISTEMA AMEIENTAL}

Os antecedentes

Embora a concessão de terras tenha ocorrido somente a partir do final do século XIX, existem registros de ocupaçāo humana na região, desde 5000 anos AP. CARDOSO e WESTPHALEN (1986), comentaram sobre vestigios de grupos, destacando-se a Tradição Humaitá (no período entre 5000 e $2500 \mathrm{AP}$ ) e Tradiçāo Tupi-Guarani (entre 500 a 1000 ), no terço inferior do rio Ivaí.

Até 1925, a maior parte das terras da regiāo noroeste do Paraná pertencia ao Estado, sendo que o processo de sua ocupaçăo efetivou-se pelas frentes de expansão cafeeira, a partir do final dos anos 40 .

Destacaram-se nesta ocupação as companhias de colonizaçâo que imprimiram uma caracteristica peculiar na forma de distribuição dos lotes rurais ou seja, propriedades de tamanho familiar, com cerca de 35 hectares, dispostas de modo a incluir uma porçâo do vale para o suprimento de água e uma porçăo do interflúvio, voltada para a estrada com a finalidade de facilitar o escoamento da produçāo da propriedade. Numa avaliaçào preliminar, esta situaçāo mostrava-se vantajosa, permitindo uma certa independència de cada propriedade. No entanto, esta forma de ocupaçáo foi um dos fatores que desencadeou, de forma violenta, os processos erosivos acelerados, seja pela divisão de propriedades com cercas, seja pelo caminho dos animais das porçōes elevadas para os córregos ou pelo traçado de estradas sem equipamentos complementares obrigatórios, tais como sistemas de drenagem (OEA, 1973).

Desconhecendo as características físicas dos solos que passaram a ocupar e imaginando a princípio, tratar-se de solos semelhantes aos derivados do basalto, a orientação do uso da terra foi altamente desastrosa, aliando-se ainda, a uma política econốmica equivocada, atrelada às flutuaçōes do mercado internacional, na busca imediata de aumento de divisas para o pais. Desta forma, 
- avanço destas frentes de expansão agricola foi impuisionado pelas altas cotaçóes do café no mercado internacional, com manipulação das taxas cambiais pela classe cafeeira, permanecendo esta situaçăo atè o inicio da década de 60 . Neste periodo, o noroeste continha $40 \%$ da populaçāo estadual e era detentor de $80 \%$ da produção de café. (OEA, 1973).

A partir desta data passou a haver a intervençăo do governo federal, criando taxas de exportaçầ, sendo que, a nivel de mercado externo, os preços do café se modificaram e o governo passou a regular também a sua produçāo; subsidiando, inclusive, a erradicaçăo de cafezais.

Na regiāo noroeste do Estado do Paraná o desestímulo governamental veio acompanhado de prejuizos relacionados a fatores ambientais, destacando-se as geadas que ocorreram em 1953 e 1955 e à erosăo acelerada nos solos derivados do Arenito Caiuá.

Uma nova paisagem passou a ser delineada pela substituiçâo de parte dos cafezais e o conseqũente aumento de áreas para pastagens e culturas temporárias.

Apesar dos inúmeros projetos, poucas açōes se efetivaram para solucionar o conjunto de problemas decorrentes, fazendo com que o próprio habitante da regiảo buscasse alternativas, sendo que, a maioria, fota dos critérios de harmonia com o meio ambiente. Assim ele passou do café, para a pastagem, milho, soja, algodăo e outras culturas $e$, quando nada deu certo, vendeu as terras e partiu para novas frentes como, por exemplo, Mato Grosso e Rondónia ou para as áreas urbanas.

Como reação a estas açōes, mudou, em parte, a estrutura fundiária da regiāo com consequientes reflexos na sua organizaçâo social, acentuadamente, a partir da década de 70 . Ocorreu um esvaziamento populacional rural, surgindo a figura de um novo trabalhador, volante e sem terra, vivendo na periferia dos núcleos urbanos enquanto grandes propriedades foram-se formando. Neste contexto, a maior parte dos cafezais transformou-se em pastos e, mais recentemente, em grandes canaviais. (OEA, 1973).

\section{PARANÁ}

\section{A NEOPAISAGEM DA REGIĀO NOROESTE DO ESTADO DO}

Tendo em vista que a vegetaçăo primária, constituida pela Fioresta Estacional Semidecidual foi praticamente extinta, eliminou-se com a mesma um dos fatores de formaçäo dos solos da regiăo noroeste, criando, certamente uma situação de desequilibrio, uma vez que os outros fatores permanecem, de maneira geral, os mesmos. De acordo com PETIT (1992), a presença de uma quantidade de calor $\theta$ umidade similares em solos que sofreram destlorestamento ou com vegetaçăo de pequeno porte, faz o ambiente evoluir de forma regressiva, permitindo que a morfogênese predomine sobre a pedogênese. No caso da regiăo noroeste, a aceleraçāo da morfogênese, criando um ambiente de alta energia, provoca a retira de material das vertentes pela erosăo laminar e em lençol que, por sua vez, ocasiona o truncamento de solos pela eliminaçào da camada superticial, conforme verificaram CARDOSO, POTTER e DEDECEK (1992). Ao mesmo tempo que ocorre a perda de camadas superficiais de araçāo do solo, a sua retirada das encostas descobertas de vegetaçắo induz a 
modificaçōes na forma das mesmas, apresentando uma certa tendëncia à concavidade, sendo que, nas bacias receptoras podem ocorrer novos processos erosivos acelerados ou mesmo reativação de antigas linhas de erosão, representadas pelas voçorocas, amplamente disseminadas na regiăo. Desta maneira, os processos erosivos acelerados pela ação antrópica, proporcionam o transporte livre dos sedimentos alterados, das porçöes superiores das encostas para os vales.

Esta ação antrópica, atuante a principio, de forma quase imperceptivel no sistema, passa a fazer parte do mesmo, na sua desestruturaçăo parcial a cerca de quatro décadas. O fluxo de baixa energia existente em presença da floresta é invertido para uma energia excessiva ao sistema, afetando os solos descobertos, pela retirada das camadas superficiais com matéria orgánica (CARDOSO, POTTER e DEDECEK, 1992). Tal situaçăo importou do passado algumas condiçōes que estavam latentes, tais como reativaçăo de voçorocas estabilizadas e semi-estabilizadas nos anfiteatros, junto às nascentes, em áreas de lineamentos geológicos. Deixou a descoberto, também, junto a estas áreas, antigos depósitos de areia sem vegetação ou com escassa cobertura vegetal, com o horizonte superficial lavado e parcialmente recobertos por material transportado das encostas, os quais constituem microdesertos edáficos, em concordância com a proposiçăo de DREGNE (1977). Estão distribuídos, espacialmente, em muitos municipios da regiăo noroeste do Paraná, na área de dominio do Arenito Caiuá (MURATOAI, 1996).

Numa avaliaçăo do uso da terra na década de 90 , evidencia-se uma situação de estabilidade relativa, tendo em vista que parte das propriedades adota mecanismos como plantio em curvas de nivel e terraceamento, no sentido de minimizar os efeitos do uso incorreto do solo durante os 40 anos de ocupação intensa da Regiăo Noroeste.

Todavia, este quadro nāo esconde os problemas advindos da dinàmica do ambiente. A cada chuva pode-se constatar este fato, pela forte coloraçăo avermelhada das águas dos rios e córregos e pelos inúmeros depósitos arenosos de baixada, formando leques colúvio-aluviais, antrópicos e temporários, que podem ser denominados de depositos tecnogênicos (OLIVEIRA, 1994), Nas encostas mais ingremes, devido à concentração de águas pluviais, aliada aos caminhos criados pelo pisoteio do gado, entre outros, săo comuns os movimentos de massa pela combinaçāo mais ativa da força gravitacional com o poder lubrificante da água. Menos percebida e pouco importante nas áreas de climas úmidos mas, merecendo consideração sob o enfoque de conservaçăo dos solos. observa-se que durante os intervalos de plantio, as partículas dos solos desnudos são, constantemente, movimentadas pelos ventos, provocando a erosāo eólica $\theta$ alterando as suas camadas superficiais.

Nestas condiçōes, todos os solos sāo afetados e, em particular, os solos referentes à classe das Areias Quartzosas que săo, por natureza, muito arenosos $\theta$ incoerentes, relacionados a zonas coletoras de água em anfiteatros. A major presença de água, aliada à açăo direta da temperatura pela auséncia de vegetaçăo nos alinhamentos onde se instala a drenagem, permite uma intensa lixiviação destes solos, percebida através de uma profunda mudança na coloraçāo que passa de avermelhado a amarelado e à areia branca, indicando perdas de elementos como o ferro. 
Outro fato a ressaltar, é de que năo existe a preocupaçăo de refiorestamento nem em áreas minimas, protegidas pela legislaçăo, como as margens e cabeceiras dos rios. Nas porçōes mais profundas de algumas voçorocas, constituindo grotóes de dificil acesso, a vegetação se recupera, mas à montante, as cabeceiras de drenagem estāo desnudas, sendo assoreadas em um novo ciclo de modelagem do relevo e, provavelmente, dando origem a novos tipos de solos, tais como os depósitos atuais de areias quartzosas, combinandose aos depósitos antigos os quais constituem, no conjunto, os microdesertos edáficos.

A principio, seria surpreeendente relacionar áreas da regiăo noroeste do Paraná a problemas de desertificaçāo, tendo em vista as condiçōes pluviométricas existentes e, ainda mais, atendo-se ao conceito de deserto, puramente climático, o qual implica numa evaporaçăo maior que a precipitaçăo pluviométrica efetiva. Na região, os períodos de seca sāo muito curtos, correspondendo, em geral, a alguns dias dos meses de inverno, acentuadamente nos meses de agosto, julho e junho (IAPAR, 1994). Justifica-se, entretanto, a discussăo sobre processos de pré-desertificação, compreendendo-os, de acordo com DREGNE (1977), como o empobrecimento geral do ecossistema, em consequência da reduçāo de biomassa, em solos deteriorados e empobrecidos.

Pelas observaçōes de campo, são inúmeros os depósitos de areia solta, quase sem cobertura vegetal, com ausência de horizonte orgânico (CARDOSO. POTTER e DEDECEK, 1992), como parte das Areias Quartzosas. Apesar de serem inadmissiveis do ponto de vista climático, são incontestáveis do ponto de vista morfopedológico e edáfico. São observáveis em campo, através de pequenas manchas esbranquiçadas, quase invisiveis nas fotografias aéreas e em imagens, a não ser de forma indireta, pela ausência de vegetaçāo, nas áreas que correspondem aos anfiteatros de erosăo.

\section{CONSIDERAÇŌES FINAIS}

A neopaisagem da região noroeste do Estado do Paraná referida à área de domínio do Arenito Caiuá, reflete o estado do sistema ambiental no que diz respeito à interaçăo de processos presentes a passados onde o homem passou a desempenhar papel fundamental. Neste contexto, torna-se possivel afirmar que passaram a atuar na regiāo noroeste do Paraná processos, os quais induzem ao reconhecimento de um novo periodo geológico, o Quinário ou Tecnógeno.

REFERÊNCIAS BIBLIOGRÁFICAS

BIGARELLA, J. J., MAZUCHOWSKI J. Z. Visão integrada da problemática da erosão. In: SIMPÓSIO NACIONAL DE CONTROLE DE EROSĀO, 3., Maringá, PR. 1985. Livro-Guia. Curitiba : ABGE/ADEA. 1985. 332 p. ilust. 
CARDOSO A.; POTTER, R. O.; DEDECEK, R. A. Estudo comparativo da degradação dos solos pelo uso agrícola no noroeste do Paraná. Pesquisa Agropecuária Brasileira. Brasilia, v. 27 n. 2, p. 349-353, fevereiro 1992.

CARDOSO, J. A.; WESTPHALEN, C. M. Atlas Histórico do Paraná. 2.ed. Curitiba: Chain, 1986

DREGNE, H.E. Desertification of arid lands. Economic Geography. 1977.53 (4).

FERNANDES, L. A . A cobertura cretácea suprabasáltica no Paraná e Pontal do Paranapanema (SP) : os Grupos Baurú e Caiuá. São Paulo, 1992. Dissertação de mestrado do Programa de Pós-Graduaçâo em Geologia Sedimentar. Instituto de Geociências. Universidade de São Paulo.

FIBGE. FUNDAÇÃO INSTITUTO BRASILEIRO DE GEOGRAFIA E ESTATISTICA. Geografia do Brasil. Região Sul. Rio de Janeiro : Diretoria de Geociências, 1990, 420 p.

GIMENEZ FILHO, A , PIRES NETO, A. G, ; AICCOMINI, C, ; DEHIRA, L, K.; MELO, M. S. de; BRAGA, T. de, O mapeamento Geológico do Bloco SF. 22T (ACS-73). In: RELATÓRIO IPT 14.845. IPT ,v. 1. Săo Paulo, 1981. 28-56.

IAPAR. Cartas climáticas do Estado do Paraná. Londrina : IAPAR, 1994 v. 18.

JUSTUS, J. D. O.: BRASIL, A. E.; HERMANN, M. L. de P. Relatório geomorfológico da Folha SF.22 Paranapanema. Florianópolis : Projeto RADAMBAASIL, 1985 (inédito).

LEITE, P. F. As diferentes unidades fitoecológicas da regiāo sul do Brasil: proposta de classificação. Curitiba, 1994. Dissertaçäo (mestrado em Engenharia Florestal). Setor de Ciências Agrarias. Universidade Federal do Paraná.

MAACK, R. Breves notícias sobre a geologia dos Estados do Paraná e Santa Catarina. Arquivos de Biologia e Tecnologia Curitiba, n. 2, p. $67-154,1947$. 
O aspecto fitogeográfico atual do Paraná e consideraçōes sobre o problema do reflorestamento. Arquivos de Biologia e Tecnologia. Curitiba, n. 8, p. 425-436, 1953.

Geografia Física do Estado do Paraná. Curitiba: Universidade Federal do Paraná. 1968. 350 p.

MURATORI, A, M. Erosão no noroeste do Paraná: uma proposta metodológica de estudo sistemático através do uso de fotografias aéreas. Curitiba, 1984. Dissertação (mestrado em Clências Geodésicas). Universidade Federal do Paraná.

; MURATORI, A.; SALAMUNI, R. Preliminary accounts about the geological implications of the "Sand-Quartz" (AQ Type), In: TROPICAL'S 85. FIRST INTERNATIONAL CONFERENCE ON GEOMECHANICS IN TROPICAL. LATERITIC AND SAPROLITIC SOILS (1985 : Brasilia). Proceedings. Brasilia : ABMS. Brasília, 1985. p. 157163.

MURATORI. A. Contribuição ao conhecimento dos fenômenos intervenientes no processo de erosão acelerada no noroeste do Paraná; propostas metodológicas de trabalho. In: SIMPÓSIO NACIONAL DE CONTROLE DE EROSÂO, 3., ATAS... Maringá, ABGE, 1985. p. 213-216.

Processos interativos entre o relevo e as Areias Quartzosas no sistema ambiental da regiāo noroeste do Paraná - Brasil. Curitiba : 1996. Tese (doutoramento em Ciências Florestais). Curso de PósGraduaçẩo em Clências Florestais. Área de Silvicultura. Setor de Ciências Agrárias. Universidade Federal do Paraná.

OEA. ORGANIZAÇÄO DOS ESTADOS AMERICANOS, Bacia do Rio da Prata. Estudo para sua planificaçāo e desenvolvimento. Estudo para controle da erosâo. Rio de Janeiro: OEA, 1973. v. 1, $217 p$.

OLIVEIRA, A. M. dos S. Depósitos tecnogênicos e assoreamento de reservatórios. Exemplo do reservatório de Capivara, rio Paranapanema, SP/Pr. São Paulo: 1994. Tese (doutoramento em Geografia). Faculdade de Filosofia, Letras e Ciências Hurnanas. Departamento de Geografia, USP. 
PETIT, M. Géographie physique tropicale. Approche aux études du milieu. Morphogenèse-paysages. Paris. Éditions KARTHALA et ACCT, 1990. $351 \mathrm{p}$.

POPP, J. H.; BIGARELLA, J. J. Formaçōes cenozóicas do noroeste do Paraná. In: SIMPÓSIO INTERNACIONAL SOBRE O QUATERNÁRIO. (1975: Curitiba-Porto Alegre). Anais da Academia Brasileira de Clências, 1975. v. 47, p. $465-472$.

TER-STEPANIAN, G. Beginning of the Technogene. Bulletin of the International Association of Engineering Geology. 1988, (38) : 133142. 